IZA DP No. 9397

Height, Weight and Well-Being for Rural, Urban and Migrant Workers in China

Wang-Sheng Lee

Zhong Zhao

October 2015 


\title{
Height, Weight and Well-Being for Rural, Urban and Migrant Workers in China
}

\author{
Wang-Sheng Lee \\ Deakin University \\ and IZA
}

Zhong Zhao

Renmin University of China

and IZA

Discussion Paper No. 9397

October 2015

\author{
IZA \\ P.O. Box 7240 \\ 53072 Bonn \\ Germany \\ Phone: +49-228-3894-0 \\ Fax: +49-228-3894-180 \\ E-mail: iza@iza.org
}

\begin{abstract}
Any opinions expressed here are those of the author(s) and not those of IZA. Research published in this series may include views on policy, but the institute itself takes no institutional policy positions. The IZA research network is committed to the IZA Guiding Principles of Research Integrity.

The Institute for the Study of Labor (IZA) in Bonn is a local and virtual international research center and a place of communication between science, politics and business. IZA is an independent nonprofit organization supported by Deutsche Post Foundation. The center is associated with the University of Bonn and offers a stimulating research environment through its international network, workshops and conferences, data service, project support, research visits and doctoral program. IZA engages in (i) original and internationally competitive research in all fields of labor economics, (ii) development of policy concepts, and (iii) dissemination of research results and concepts to the interested public.
\end{abstract}

IZA Discussion Papers often represent preliminary work and are circulated to encourage discussion. Citation of such a paper should account for its provisional character. A revised version may be available directly from the author. 


\section{ABSTRACT}

\section{Height, Weight and Well-Being for Rural, Urban and Migrant Workers in China*}

In general, the happiness literature has paid little attention to the relationship between physical appearance and well-being. In this paper, we examine the link between weight, height and well-being for three distinct samples in China given that attractiveness effects likely vary greatly across sociocultural contexts. As China has recently undergone rapid economic transformation in the urban areas, this empirical exercise is particularly interesting because it can highlight how changing social norms have affected the relationship between physical appearance and subjective well-being. For the rural and migrant samples, we find that for both men and women, big and tall individuals have higher levels of well-being. This is consistent with the notion that the strong are better off when more labor intensive work is the norm. For the urban sample and for urban males in particular, no well-being penalty is found for being obese, unlike previous results based on Western samples. It is very likely that the unique Chinese cultural practice of network building banquets and feasting is behind this finding.

JEL Classification: $\quad 110,130$

Keywords: China, subjective well-being, height, weight, semi-parametric

Corresponding author:

Wang-Sheng Lee

Deakin University

Department of Economics

70 Elgar Road

Burwood, VIC 3125

Australia

E-mail: wang.lee@deakin.edu.au

\footnotetext{
* Zhong Zhao acknowledges financial support from the Natural Science Foundation of China (Grant No. 71173227). The collection of the Rural Urban Migration in China (RUMiC) data used in this paper is financed by IZA, ARC/AusAid, the Ford Foundation, and the Ministry of Labor and Social Security of China.
} 


\section{Introduction}

China has experienced remarkable economic growth in the past two decades and a significant proportion of its population has seen large increases in their standard of living. The traditional focus in economics has been to use indicators such as the Gross Domestic Product per capita to measure well-being. Based on this metric of well-being, one might expect large increases in the life satisfaction of the population in China form the 1990s onwards. Yet, somewhat paradoxically, there is no evidence of an increase in life satisfaction of the magnitude that might have been expected to result from the fourfold improvement in the level of per capita consumption that has occurred (Brockmann et al. 2009; Easterlin et al. 2012). Another paradox regarding happiness levels in China is that despite having an urbanrural income ratio that exceeds 3:1, average happiness is no higher in urban than in rural China and is actually lower (Knight and Gunatilaka 2010a).

While much attention in economics has focused on the issue of whether money makes people happy and relative income comparisons (e.g., Easterlin 2001; Clark et al. 2008; Stevenson and Wolfers 2008), there is also a large literature on the determinants of subjective well-being (SWB) that suggests roles for several other factors. These include unemployment, poor health and relationship breakdowns (e.g., see Diener et al. 1999; Frey and Stutzer 2002; Dolan et al. 2008, Akee et al. 2015).

There have been several studies of factors affecting SWB in China that use large datasets that are broadly representative of the general public. The majority of these studies focus on urban residents (Appleton and Song 2008; Smyth et al. 2010; Wang and VanderWeele 2011; Jiang et al. 2012; Huang et al. 2015; Qian and Qian 2015; Akee et al. 2015). But there have also been a few studies that examine the determinants of happiness for rural residents (Knight et al. 2009) and rural-urban migrants (Gao and Smyth 2011; Knight and Gunatilaka 2010b; Nielsen et al. 2010; Akay et al. 2012).

In general, the happiness literature has paid little attention to the relationship between physical appearance and SWB. An early study by Diener et al. (1995) found that among college students there was only a small relationship between physical attractiveness and SWB. Yet, physical appearance is one of the only factors identified by Frederick and Loewenstein, (1999) that can have a permanent effect on altering baseline happiness. ${ }^{1}$ For example, with regards to interventions that alter one's physical appearance, enduring improvements of SWB

\footnotetext{
${ }^{1}$ Set point theory predicts that well-being tends to fluctuate around a stable level over time (Cummins, 1998; Fujita and Diener, 2005). In response to positive events, an individual's well-being might rise transiently but then will revert to this stable level or set point. Likewise, after experiencing negative events, an individual's well-being might decline but will eventually return to the set point.
} 
have been uncovered six months after cosmetic surgery (e.g., Cole et al. 1994). In addition, research has documented weight bias toward obese individuals from romantic partners (Boyes and Lattner 2009) and that weight bias increases the risk of depression, anxiety and low self-esteem (Friedman et al. 2005).

A person's immediate physical appearance can arguably be conveniently summarized using a combination of height and weight. For example, many dating websites typically focus on revealing the values of these two attributes of each individual to prospective partners. It has also been suggested that the body mass index (BMI) is a major factor in determining physical attractiveness for women (Tovée et al., 1998). To date, only a handful of papers have focused on the relationship between height, weight and SWB in economics and the literature generally focuses on either the link between height and SWB or weight and SWB but not height and weight considered together.

Most empirical studies that have explored the relationship between obesity and SWB (Oswald and Powdthavee 2007; Stutzer 2007; Clark and Etilé 2009; Katsaiti 2012; Forste and Moore 2012) find that SWB is significantly negatively affected by obesity after taking into account the effect of all other relevant individual-level covariates such as age and education. Böckerman et al. (2015), however, finds that the adverse effects of obesity on health and functioning are the primary explanation for the observed negative relationship between obesity and SWB.

There are also several empirical studies examining the relationship between height and SWB that provide mixed results. Deaton and Arora (2009) using over 400,000 pooled observations from the Gallup-Healthways Well-Being Index finds that taller US individuals are happier whether this is unconditional or conditional on socio-demographic and income variables. Carrieri and De Paola (2012) finds that taller men and women in Italy are happier when only basic demographic characteristics (age, marital status, any children) are conditioned upon. However, controlling for economic and health conditions, they find that height is not associated with the well-being of either men or women. Using data from Indonesia, Sohn (2014) finds that for men, some effects of height remain even when accounting for an extensive set of covariates. By contrast, for women, the inclusion of covariates is enough to remove the effects of height on happiness.

Attractiveness effects likely vary greatly across sociocultural contexts. Dion et al. (1990) propose a sociocultural hypothesis that physical attractiveness is less likely to be a salient evaluative cue in cultural contexts where collectivism, rather than individualism, is the basis for the dominant system of values. Plaut et al. (2009) suggest that attractiveness effects 
are stronger in urban environments as such settings enhance the importance of attractiveness for social connection - an important source of SWB. In urban areas, people have contact with a larger pool of potential partners for social connection and are freer to choose close friends than people in rural areas. This 'free market' of social life in urban settings might allow attractive people to create more satisfying social connections. In contrast, personal choice figures less prominently in relationship constructions in rural areas as many relationships involve non-voluntary extended family ties. Plaut et al. (2009) find using US survey data that among female urban respondents, greater conformity to cultural ideals of attractiveness (i.e., lower waist-to-hip ratio) was positively associated with SWB, and that no such relationship was found for female rural respondents. In this paper, we examine more closely the relationship between height, weight and SWB in contemporary China. By utilizing three different samples in China - a rural-urban migrant sample, a rural sample and an urban sample - we aim to better understand how different environments and social contexts moderates the relationship between physical appearance and SWB.

Since the early 1980s, extensive economic reforms have transformed China into a pseudo-capitalist market economy. According to Xu and Feiner (2007), China's connection to the global economy has had additional far-reaching effects that are partly reflected in new words that were introduced to everyday language. One of these terms is the increasingly ubiquitous meinü jingji (beauty economy). Broadly speaking, meinü jingji signifies the marketplace in which young, attractive women are used to promote commercial products and services and refers to everything from model competitions to advertisements, cosmetics, plastic surgery, beauty and healthcare services, and television and cinema that link women's appearance with the economy. In China, expenditure on beauty and personal care products tripled between 2000 and 2010 and has benefited by rapid economic development and growing household income. The increased spending on beauty products is indicative of a rising awareness of the relationship between personal appearance and well-being among consumers. $^{2}$

Some scholars (Moore 2005; Yan 2010) have described how social and economic changes in China have already transformed the country toward a much more individualistic society. Using data from 1990 to 2007 from the World Values Survey, Steele and Lynch (2013) examine whether individualistic (vs. collectivistic) factors have become increasingly important in predicting SWB in China. They find that more individualistic explanatory

\footnotetext{
${ }^{2}$ Euromonitor International - “Beauty and Personal Care in China”, May 2014.
} 
factors - income, marital status, employment status, and health - have become more important for SWB over time, and factors reflecting respondents' collectivist sentiment national pride and support for collectivist policies - have become less important. As the country increasingly places more emphasis on individualistic values, although each of the three different samples we consider encounter different environments, the relationship between physical appearance and SWB is likely to become more important over time.

In modern day China, competition for non-agricultural jobs is intense. The Chinese urban labor market is currently in a process of transition from an administered system, in which labor was allocated and wages were set institutionally, to one in which market forces play a role. Currently, over seven million university graduates enter the Chinese labor market annually and many job applicants for entry level jobs are equally well qualified on paper. ${ }^{3}$ Any extra edge that a job applicant might have can play an important role in labor market success. Many media articles have highlighted issues surrounding the tight labor market in urban China facing young college graduates. ${ }^{4}$

Unlike many western developed countries, contemporary job advertisements in China regularly feature explicit discrimination and stipulate requirements for attributes such as age, gender and height. In 8\% of the one million job ads examined by Kuhn and Shen (2013) from Zhaopin.com (the third largest online job board in China that is known for catering to young, highly educated workers looking for well-paid private sector jobs), it was explicitly requested that the applicant be physically attractive. In a large-scale field experiment to investigate how Chinese firms respond to the facial attractiveness and gender of job candidates who submit applications through Internet job boards, Maurer-Fazio and Lei (2015) find a substantial premium on facial attractiveness. Applications with attractive photos attached received substantially higher rates of callbacks across gender, occupation, and location.

There appears to be a clear advantage to being physically attractive in modern day China. Although we do not have measures of facial beauty, we use height and weight as proxies for physical appearance in our empirical analysis to examine the link between physical appearance and SWB.

\footnotetext{
${ }^{3}$ This is roughly equivalent to the population size of Singapore and about twice the size of its labor force. One can perhaps better appreciate the magnitude of the problem when one imagines this to be an annual issue, where a fresh cohort of graduates is looking to replace twice the size of the entire workforce in Singapore.

${ }^{4}$ See, for example, the article in the 23 May 2013 issue of the Atlantic Magazine "Why Chinese College Graduates Aren't Getting Jobs." It highlights a case where one journalism student “made it through the resume selection process and the written exams to the last rounds of interviews, but was eliminated during the physical examination."
} 
The main contributions of the paper are twofold. First, to our knowledge, the link between height/weight and SWB has not been studied for China before. We present in this paper the link for three distinct samples in China - rural, urban and rural-urban-migrants. Second, in addition to conventional results based on linear models, a more complete analysis of the link between SWB and height/weight is done using semi-parametric methods. This helps provide a fuller picture of various height/weight combinations that are associated with higher levels of SWB.

The rest of this paper is structured as follows. Section 2 provides information on the data we use for our empirical analysis and presents relevant descriptive statistics. In Section 3, we describe the empirical methods used. Section 4 reports the empirical results. The final section concludes.

\section{Data}

The data used in this paper is from the Survey on Rural Urban Migration in China (RUMiC), which is probably the most representative survey on migrant households in China. It is one of few surveys consisting of three independent surveys: the Urban Household Survey (UHS), the Rural Household Survey (RHS) and the Migrant Household Survey (MHS). The RHS comprises around 8,000 households, while the UHS and MHS each involve around 5,000 households. Urban (rural) residents are individuals who possess urban (rural) resident permits (hukou). A migrant is defined as an individual who has rural hukou, but is living in a city at the time of the survey. ${ }^{5}$

The RUMiC survey covers principal migrant sending and receiving regions. The RHS was conducted in villages across nine provinces, while the UHS and MHS were carried out in nineteen and fifteen cities, respectively (see Akgüc at el. (2014) for details). All three samples gather information on household and personal characteristics, detailed health status, employment, income, training and education of adults and children, social networks, family and social relationships, life events, mental health measures of the individuals and, for migrants, information related to migration history. Questionnaires have been made comparable across the three samples which therefore allow for comparisons to be made across groups. In this paper, we use data from the first wave conducted in 2008 which covers 18,000 Chinese households. The first wave of survey interviews took place before the 2008

\footnotetext{
${ }^{5}$ Migrants are typically clustered in dormitories near factories and construction sites, often without a registered address. For each city, a sample of migrant workers was randomly selected within each workplace, based on their birth month.
} 
global financial crisis, allowing us to avoid any complications of the crisis that might affect SWB.

The SWB measure we use in this paper is based on the 12 question version of the General Health Questionnaire (GHQ; Goldberg and Williams 1988). The GHQ is designed to assess current mental well-being by assessing normal 'healthy' functioning and the appearance of new, distressing symptoms. Prior use of the GHQ-12 as a measure of SWB in the economics literature include Clark and Oswald (1994; 2002) and Akay et al. (2012). Previous research has shown the GHQ-12 to have good psychometric properties on adult samples in 15 countries around the world in which a total of 11 languages were spoken, including China (Goldberg et al. 1997).

We use the Likert scoring method and sum up the answers to 12 questions of the General Health Questionnaire to construct the GHQ-12 measure of mental health. Each GHQ question is coded from 1 to 4 . Hence, the lowest score is 12 and the highest is 48 . We reverse the scale so that the higher scores indicate higher well-being. ${ }^{6}$

This paper considers the association between height, weight and SWB for the three distinct samples. We run separate regressions for women and men, since the effect of height and weight might differ by gender. We focus on males and females aged between 25 and 60 . The sample includes all household heads and the spouses of all married household heads. Descriptive statistics for the three samples are provided in Table 1.

As was seen in Knight and Gunatilaka (2010a), in our data, average SWB is higher in rural than in urban China for males, despite the fact that average per capita household income is more than three times higher for urban males. Unlike in many Western samples, the proportion of obese individuals $(\mathrm{BMI} \geq 30)$ is not high, although $15.8 \%$ of urban females and $25 \%$ of urban males are considered to be overweight. The proportion overweight is considerably lower in the rural and rural-urban migrant sample. As expected, the urban sample has considerable more years of education (10.9 for females and 11.6 for males) compared to the rural sample (6.6 for females and 7.7 for males) or migrant sample (8.2 for females and 8.9 for males). Reflecting the one-child policy for urban China that was more strictly enforced, the majority of urban families have one child, as compared to families in non-urban areas who tend to have more children. Across all three samples, the majority of individuals self-report that they have average health or better. Finally, in the rural sample, the

\footnotetext{
${ }^{6}$ We also experimented with using the GHQ scoring method (0-0-1-1) as an alternative and found similar results. The Likert scoring method will produce a wider and smoother score distribution (Goldberg et al. 1997) and is useful in conducting our semi-parametric estimation in the next section.
} 
lower employment rates (21.5\% of females and $38.5 \%$ of males) reflect the fact that most rural workers work on farms with a minority engaged in paid non-agricultural work.

\section{Methods}

To estimate the relationship between height and SWB, we use the following equation for SWB that is estimated using OLS:

$$
S W B_{i}=\alpha+\delta \text { Height }_{i}+\beta X_{i}+\varepsilon_{i}
$$

where $S W B_{i}$ is the GHQ-12 measure of mental distress, Height is height measured in centimeters, $X_{i}$ is a standard set of covariates (age, marital status, education, income, selfassessed health, number of children, employment status) used in the height/BMI and SWB literature, and $\varepsilon_{i}$ is a residual term. A similar OLS model is used to estimate the relationship between BMI and SWB:

$$
S W B_{i}=\alpha+\delta B M I_{i}+\beta X_{i}+\varepsilon_{i}
$$

In Equation (2), $B M I_{i}$ can be expressed as a continuous variable or as a categorical variable representing the widely used obesity classifications in the public health literature (BMI < 18.5, BMI 18-24.9, BMI 25-29.9, BMI $\geq 30$ ). Both Equations (1) and (2) are commonly used in the literature that was surveyed in the previous section. The results from estimating these models allow us to compare our findings based on data from China with estimates from other countries.

A potential issue in using Equation (1) to estimate the association between height and SWB and Equation (2) to estimate the association between BMI and SWB is endogeneity. There could exist unobserved factors that simultaneously affect both height/BMI and SWB. Previous researchers have dealt with the endogeneity problem using panel data or instrumental variables. For example, a good overview of empirical strategies used in obesity research is discussed in Auld and Grootendorst (2011), who highlight that causal inference in obesity research is very challenging because body weight is an outcome that cannot be experimentally manipulated. As we have neither panel data nor good instruments at our 
disposal, we focus on the reduced-form relationships in this paper, as well as a more flexible semi-parametric estimation procedure.

An alternative to the reduced-form OLS approach we use in this paper is to estimate the following equation for SWB:

$$
S W B_{i}=f\left(\text { Height }_{i}, \text { Weight }_{i}\right)+\beta X_{i}+\varepsilon_{i}
$$

In equation (3), the function $f($.$) is a continuous but unspecified function of height and$ weight that is estimated from the data. Recent guidelines released in 2013 by the American College of Cardiology, the American Heart Association, and the Obesity Society highlight the limitations of solely relying on the BMI formula (weight/height ${ }^{2}$ ) and suggest the use of a joint approach that is based on BMI and waist circumference as a health risk indicator (Jensen et al. 2014). The advantage of the semi-parametric approach is that it is able to analyse joint variation in height and weight without imposing any restrictive functional forms. As discussed in Lee (2014), such an approach can be useful in combining the two distinct literatures that focus on the effects of height and BMI separately. .

As the model is additively separable and includes a non-parametric component, it is sometimes also referred to as a generalized additive model (GAM) in the statistical literature. This is because it extends a generalized linear model by replacing the linear functional form with an unknown functional form determined by the data. Complicated non-linear problems can be easily accommodated, even for models with many explanatory variables. GAMs are able to accommodate the interaction of two or more predictors in a way that is conceptually comparable to interactions in a linear regression model. The joint smooth function of the predictors can be specified using tensor product smooths which is optimal for variables measured on different scales (Wood, 2006a). We use this interaction to map out the height and weight combinations that are related to different levels of SWB. When we interact height/weight with income, this model can also provide us insights on the heterogeneous relationship between height, weight and SWB at different income levels.

In this paper, we focus on using a P-splines for performing our empirical analysis (Eilers and Marx, 1996). P-spline smoothing models are fit using penalized likelihood maximization in which the model likelihood is modified by the addition of a penalty for each smooth function, penalizing its 'wiggliness'. As discussed by Eilers and Marx (1996), when a large number of equally spaced knots and a large number of splines are used, the primary role 
of the basis function is to serve as a convenient smooth interpolation device. The choice of the smoothing parameter $\lambda$ or the amount of smoothing that is applied to the data can strongly affect the fit of the model. The smoothness of $f($.$) is calculated with the aim of$ optimal balance between the fit to the data versus a penalty for excessive "wiggliness" of the functions. In this paper, we estimate the smoothing parameter using a restricted maximum likelihood (REML) approach (Ruppert et al. 2003; Wand 2003). The mgcv library (Wood 2006b) in $\mathrm{R}$ is used to estimate the models.

\section{Results}

The simple descriptive relationships between height and SWB as well as between BMI and SWB are provided in Table A.1 in the appendix, where only controls for provinces are included. These results help provide an initial overview of whether taller people have higher well-being and if obese people have lower well-being.

Similar to the literature discussed in Section 1 of the paper, we find statistically significant unconditional associations between height and SWB. The inclusion of covariates, however, is enough to reduce the magnitude of the associations and remove statistical significance in all but one instance. In examining the relationship between height and SWB (Table 2) when other individual characteristics are conditioned upon, the only significant association we find is for male migrants, where a $10 \mathrm{~cm}$ increase in height is associated with a 0.43 point increase in the GHQ-12 score (which is equivalent to $1.1 \%$ when expressed as a percentage of the mean for male migrants). The signs of the other coefficients in Table 2 are, in general, as one would expect. Individuals with higher household income, education, who are married and very good health have higher SWB.

When expressed as a continuous variable, BMI appears to have a more significant relationship with SWB in China (Table 3) than height does after conditioning on individual characteristics. For rural males, as well as urban males and females, we find small, positive and significant associations between BMI and SWB. For example, for urban males, a one point increase in BMI is associated with a 0.093 point increase in the GHQ-12 score. However, when using standard BMI cutoffs to denote the overweight and obese (Table 4), the results change dramatically and the previously found statistically significant associations are no longer significant. Instead, only the coefficient for the obese for female migrants is found to be weakly significant at the $10 \%$ level. As can be seen in Table A.1 in the appendix, the inclusion of covariates is not driving this result. Instead the non-linearities introduced by using the BMI cutoffs appear to overturn the significant results based on using BMI as a 
continuous variable. Although it might appear puzzling to have such incongruous results, an explanation can be found by looking at the descriptive statistics in Table 1. In China, the majority of the population has BMI values between 18 and 24.9 which classifies them as being in the healthy weight category. The results in Table 3 are therefore mainly driven by observations in this BMI category where there exists a positive and significant relationship between BMI and SWB. ${ }^{7}$

However, the BMI approach necessarily imposes functional form assumptions. In order to relax the parametric assumption, we turn to the semi-parametric results based on Equation (3). The complete results of the model are not shown and we focus on plotting the function $f($.) for the different samples, which is the interaction of height and weight. The plots of the interaction term are based on iso-contour plots that allow one to visualize how various combinations of height and weight are associated with different levels of GHQ-12 scores, conditional on other covariates.

For male migrants (Figure 1, top panel), the direction of the iso-contour lines suggests that taller and heavier males have slightly higher levels of SWB. For female migrants (Figure 1, bottom panel), a similar result is found. For example, reading from the plot, one can see that a 1.60 meters tall female migrant who weighs $70 \mathrm{~kg}$ has a lower GHQ-12 score than a female migrant who is the same height but weighs $80 \mathrm{~kg}$. The GHQ-12 score for the former is about 39.5 but is about 40.5 for the latter. Males and females in rural China (Figure 2) who are big and tall also appear to have higher levels of SWB. As for migrants, these results are not surprising given that many migrants and rural people are involved in manual labor and other laborious tasks that require strength. Being viewed as more competent in these tasks can help increase their GHQ-12 score.

The results for urban males (Figure 3, top panel) is a little more unexpected in that there is a slight positive gradient in weight which suggests that holding height constant, heavier urban males have slightly higher levels of SWB. These results are inconsistent with the literature that is primarily based on Western samples, which generally finds that SWB is negatively associated with obesity. Yet, these results are reasonable when one appreciates the role of feasting and drinking in the context of China. The practice of yingchou (work-related

\footnotetext{
${ }^{7}$ We also estimated the models presented in Tables 2 to 4 excluding health as anthropometric measurements are likely to be related to health. This allows us to estimate a total effect of height or BMI on SWB. In general, for the regressions involving SWB and height, the results are quite similar but the coefficients on height are marginally larger when health is excluded from the model. A similar pattern can be seen in the regressions involving SWB and BMI, although for urban females, the coefficient on BMI loses its significance and is smaller in magnitude.
} 
banqueting and entertaining) has long existed in Chinese history. Since the Song dynasty (960-1279), men have relied on this cultural scenario to develop networks and advance their interests. The alcohol consumed at dinners and banquets in contemporary China has maintained its historical role in establishing the bonds of trust that allow Chinese men to negotiate and cooperate with one another (e.g., see Uretsky 2008). Gaining weight is likely a simple reflection of attending many yingchou sessions and weight is therefore likely to be positively correlated with a man's social standing in urban China. In addition, for men, a high income "represents the essence of masculinity: the higher the income, the more superior his manliness” (Hinsch 2013: 163). This is especially true in China since China was still a very poor country until only 30 years ago. One of the famous slogans used when China started its economic reform in 1978 was that "getting rich is glorious." Being overweight or obese is therefore not stigmatized as long as one is rich and it can be viewed as indicating a lack of wants. In Figure A.1 (top panel) in the appendix, the iso-contour plot reveals that there is a group of men with middle/high incomes that have high levels of SWB, despite being obese $(\mathrm{BMI}>30)$.

For urban females (Figure 3, bottom panel), big and tall urban women (top right of the plot) have lower SWB levels, unlike their counterparts in the rural and migrant sample. There appears to be a local peak in SWB levels for women who are approximately between 1.55 to 1.70 meters tall and who weigh between 50 to $65 \mathrm{~kg}$. These are height and weight ranges that one would generally associate with being physically attractive for females (equivalent to BMI values between 21-25). According to $\mathrm{Xu}$ and Feiner (2007), Chinese women today are expected to possess physical beauty according to an Anglo-European standard. Younger generations of Chinese women are becoming increasingly more aware of their bodies and the pursuit of beauty is no longer deemed a bourgeois decadence as it was in the Communist era.

However, there are also some women who are below 1.60 meters tall and who weigh more than $65 \mathrm{~kg}$ that have higher levels of SWB. Based on BMI classifications, these women will be considered overweight or obese. As for urban men, these results for urban women could be a reflection of the yingchou culture and their economic success. Although the family burden has traditionally been on the shoulders of the Chinese men, with the large influx of women into the professional labor force following China’s rapid economic development, many women were expected to join their male colleagues in frequent guanxi-building banquets (Mason, 2013). ${ }^{8}$ As can be seen in the bottom panel of Figure A.1 in the appendix,

\footnotetext{
${ }^{8}$ In essence, guanxi can be defined as being about building a network of mutually beneficial relationships.
} 
BMI plays a secondary role to household income in determining levels of SWB for urban women; a higher income is associated with higher levels of SWB regardless of one's BMI value. This interesting finding reflects the fact that many Chinese females are playing a more and more important role that goes beyond their traditional family roles.

To summarize, both a standard OLS approach and a semi-parametric approach suggest a rather unusual result for urban Chinese men and women. Based on the standard OLS approach, we find that urban men and women who have higher levels of BMI are found to have significantly higher levels of SWB (Table 3). Being in the overweight or obese category incurs no penalty on SWB (Table 4). The semi-parametric approach helps further clarify our understanding of this result. For urban males, there is a clear correlation between weight and SWB across all levels of height (Figure 3, top panel). For urban females, the weaker statistically significant association between BMI and SWB found in the OLS approach (Table 3) is a result of two competing forces that are made clear in Figure 3 (bottom panel). While there is evidence that having a proportionate body size and being physically attractive by Western standards is related to higher SWB, at the same time, being overweight or obese has no adverse consequences on SWB if this is a result of having higher income.

\section{Conclusion}

The relationship between physical appearance and SWB has not been a focus in the happiness literature despite the billions that are being spent in the beauty and cosmetics industries every year, and evidence that permanent improvement in one's physical appearance can change one's set point of individual well-being. In this paper, using height and weight as a proxy for physical appearance, we attempt to fill this gap in the literature by examining the link between physical appearance and SWB for three distinct samples in China. As China has recently undergone rapid economic transformation in the urban areas, this empirical exercise is particularly interesting because it can highlight how changing social norms have affected the relationship between physical appearance and SWB.

For the rural and migrant samples, we find that for both men and women, big and tall individuals have higher levels of SWB. This is consistent with the notion that the strong are better off when more labor intensive work is the norm. For the urban sample and for urban males in particular, no well-being penalty is found for being obese. It is very likely that the unique Chinese cultural practice of guanxi building banquets and feasting is behind this finding. Previous results seen in the literature based on Western samples suggest that obesity is related to lower levels of well-being. As China continues its rapid economic growth and 
takes its place as the largest economy in the world, it remains to be seen if Western ideals of beauty and physical appearance will eventually become more important in affecting wellbeing levels in China. 


\section{References}

Akee, R., Zhao, L. \& Zhao. Z. (2015). Unemployment and its effects on unhappiness: unintended consequences of China's new labor contract law. unpublished manuscript, School of Labor and Human Resources, Renmin University of China.

Akgüc, M., Giulietti, C. \& Zimmermann, K. (2014). The RUMiC longitudinal survey: fostering research on labor markets in China, IZA Journal of Labor and Development, 3:5.

Akay A, Bargain, O. \& Zimmermann, K. (2012). Relative concerns of rural-to-urban migrants in China. Journal of Economic Behavior and Organization, 81(2), 421-441.

Anderson, S., Adams, G. \& Plaut, V. (2008). The cultural grounding of personal relationship: The importance of attractiveness in everyday life. Journal of Personality and Social Psychology, 95(2), 352-368.

Appleton, S. \& Song, L. (2008). Life satisfaction in urban China: Components and determinants. World Development, 36(11), 2325-2340.

Auld, C. and P. Grootendorst. (2011). Challenges for causal inference in obesity research. The Oxford Handbook of the Social Science of Obesity. Cawley, J. (ed.). Oxford University Press: UK.

Böckerman, P., Johansson, E., Saarni, S. \& Saarni, S. (2014). The negative association of obesity with subjective well-being: Is it all about health? Journal of Happiness Studies, 15, 857-867.

Boyes, A \& Latner, J. (2009). Weight stigma in existing romantic relationships. Journal of Sex and Marital Therapy, 35: 282-293.

Brockmann, H., Delhey, J., Welzel, C., \& Yuan, H. (2009). The China puzzle: Falling happiness in a rising economy. Journal of Happiness Studies, 10(4), 387-405.

Carrieri, V \& Paola, M. (2012). Height and subjective well-being in Italy. Economics and Human Biology, 10, 289-298.

Clark, A. \& Etilé, F. (2009). Happy house: Spousal weight and individual well-being. Journal of Health Economics, 30(5), 1124-1136.

Clark, A., Frijters, P. \& Shields, M. (2008). Relative income, happiness and utility: an explanation of the Easterlin paradox and other puzzles. Journal of Economic Literature, 46 (1), 95-144.

Clark, A. \& Oswald, A. (1994). Unhappiness and unemployment. Economic Journal, 104(424), 648-659.

Clark, A. \& Oswald, A. (2002). A simple statistical method for measuring how life events affect happiness. International Journal of Epidemiology, 31(6), 1139-1144. 
Cole, R., Shakespeare, V., Shakespeare, P. \& Hobby, J. (1994). Measuring outcomes in lowpriority plastic surgery patients using Quality of Life indices. British Journal of Plastic Surgery, 47(2), 117-121.

Cummins, R. (1998). The second approximation to an international standard of life satisfaction. Social Indicators Research, 35, 179-200.

Deaton, A. \& Arora, R. (2009). Life at the top: The benefits of height. Economics and Human Biology, 7(2), 133-136.

Diener, E., Suh, E., Lucas, R. \& Smith, H. (1999). Subjective well-being: Three decades of progress. Psychological Review, 125(2), 276-302.

Diener, E., Wolsic, B. \& Fujita, F. (1995). Physical attractiveness and subjective well-being. Journal of Personality and Social Psychology, 69(1), 120-129.

Dion, K., Pak, A. \& Dion, K. (1990). Stereotyping physical attractiveness: A sociocultural perspective. Journal of Cross-Cultural Psychology, 21(3), 158-179.

Dolan, P., Peasgood, T. \& White, M. (2008). Do we really know what makes us happy? A review of the economic literature on the factors associated with subjective wellbeing. Journal of Economic Psychology, 29(1), 94-122.

Easterlin, R. (2001). Income and happiness: Towards a unified theory. Economic Journal, 111(743), 465-484.

Easterlin, R., Morgan, R., Switek, M. \& Wang, F. (2012). China's life satisfaction, 19902010. Proceedings of the National Academy of Sciences, 109(25), 9775-9780.

Eilers, P. \& Marx, B. (1996). Flexible smoothing with B-splines and penalties (with comments and rejoinder), Statistical Science, 11(2), 89-121.

Forste, R. \& Moore, E. (2012). Adolescent obesity and life satisfaction: Perceptions of self, peers, family, and school, Economics and Human Biology, 10(4), 385-394.

Frederick, S. \& Loewenstein, G. (1999). Hedonic adaptation. In D. Kahneman, Diener, E. \& Schwarz, N. (Eds.) Well-being: the foundations of hedonic psychology (pp. 302-29). New York: Russell Sage.

Frey, B. \& Stutzer, A. (2002). What can economists learn from happiness research? Journal of Economic Literature, 40(2), 402-435.

Friedman, K, Reichmann, S., Costanzo, P, Zelli, A., Ashmore, J. \& Musante, G. (2005). Weight stigmatization and ideological beliefs: relation to psychological functioning in obese adults. Obesity Research, 13: 907-916.

Fujita, F. \& Diener, E. (2005). Life satisfaction set point: Stability and change. Journal of Personality and Social Psychology, 88(1), 158-164. 
Gao, W. \& Smyth, R. (2011). What keeps China's migrant workers going? Expectations and happiness among China's floating population. Journal of the Asia Pacific Economy, 16(2), 163-182.

Goldberg, D. \& Williams, P. (1988). A user's guide to the General Health Questionnaire. NFER-Nelson, UK.

Goldberg, D., Gater, R., Sartorius, N., Ustun, T., Piccinelli, M., Gureje, O. \& Rutter, C. (1997). The validity of two versions of the GHQ in the WHO study of mental illness in general health care. Psychological Medicine, 27, 191-197.

Hinsch, B. (2013). Masculinities in Chinese history. Lanham, MD: Rowman and Littlefield.

Huang, J., Wu, S. \& Deng, S. (2015). Relative income, relative assets, and happiness in urban China. Social Indicators Research, DOI: 10.1007/s11205-015-0936-3.

Jensen M., Ryan, D., Apovian, C., et al. (2014). 2013 AHA/ACC/TOS guideline for the management of overweight and obesity in adults: a report of the American College of Cardiology/American Heart Association Task Force on Practice Guidelines and The Obesity Society. Circulation, 129: S102-S138.

Jiang, S., Lu, M., \& Sato, H. (2012). Identity, inequality, and happiness: Evidence from urban China. World Development, 40(6), 1190-1200.

Katsaiti, M. (2012). Obesity and happiness. Applied Economics, 44, 4101-4114.

Knight, J., Song, L., \& Gunatilaka, R. (2009). Subjective well-being and its determinants in rural China. China Economic Review, 20(4), 635-649.

Knight, J. \& Gunatilaka, R. (2010a). The rural-urban divide in China: income but not happiness? Journal of Development Studies, 10(28), 471-493.

Knight, J. \& Gunatilaka, R. (2010b). Great expectations? The subjective well-being of rural urban migrants in China. World Development, 38(1), 114-124.

Kuhn, P. \& Shen, K. (2013). Gender discrimination in job ads: evidence from China, Quarterly Journal of Economics, 128(1), 287-306.

Lee, W. (2014). Big and tall: Is there a height premium or obesity penalty in the labor market? IZA Discussion Paper No. 8606, Bonn: Germany.

Mason, K. (2013). To your health! Toasting, intoxication and gendered critique among banqueting women. The China Journal, 69, 108-33.

Maurer-Fazio, M. \& Lei, L. (2015). “As rare as a panda”: How facial attractiveness, gender, and occupation affect interview callbacks at Chinese firms. International Journal of Manpower, 36(1), 68-85.

Moore, R. (2005). Generation Ku: Individualism and China's millennial youth. Ethnology, 44(4), 357-376. 
Nielsen, I., Smyth, R., \& Zhai, Q. (2010). Subjective well-being of China’s off-farm migrants. Journal of happiness studies, 11(3), 315-333.

Oswald, A. \& Powdthavee, N. (2007). Obesity, unhappiness, and the challenge of affluence: Theory and evidence. Economic Journal, 117(6), F441-F459.

Plaut, V., Adams, G. \& Anderson, S. (2009). Does attractiveness buy happiness? It depends on where you're from. Personal Relationships, 16(4), 619-630.

Qian, Y \& Qian, Z. (2015). Work, family, and gendered happiness among married people in urban China. Social Indicators Research, 121(1), 61-74.

Rankin, M., Borah, G., Perry, A. \& Wey, P. (1998). Quality-of-life outcomes after cosmetic surgery. Plastic and Reconstructive Surgery, 102(6), 2139-45.

Ruppert, D., Wand, M. \& Carroll, R. (2003). Semiparametric regression. Cambridge: Cambridge University Press.

Smyth, R., Nielsen, I., \& Zhai, Q. (2010). Personal well-being in urban China. Social Indicators Research, 95: 231-251.

Sohn, K. (2014). Height and happiness in a developing country. Journal of Happiness Studies, forthcoming. DOI: 10.1007/s10902-014-9566-8.

Steele, L. \& Lynch, S. (2013). The pursuit of happiness in China: Individualism, Collectivism, and Subjective Well-Being During China's Economic and Social Transformation. Social Indicators Research, 114, 441-451.

Stevenson, B., \& Wolfers, J. (2008). Economic growth and subjective well-being: Reassessing the Easterlin Paradox. Brookings Papers on Economic Activity, 2008(1), 1-87.

Stutzer, A. (2007). Limited self-control, obesity and the loss of happiness. IZA Discussion Paper No. 2925, Bonn: Germany.

Tovée, M., Reinhardt, S. Emery, J. \& Cornelissen, P. (1998). Optimal BMI and maximum sexual attractiveness. Lancet, 352(9127), 548.

Uretsky, E. (2008). Mobile men with money: The socio-cultural and politico-economic context of 'high-risk' behavior among wealthy businessmen and government officials in urban China, Culture, Health and Sexuality, 10(8), 801-14.

Wang, P. \& VanderWeele, T. (2011). Empirical research on factors related to the subjective well-being of Chinese urban residents. Social Indicators Research, 101, 447-459.

Wood, S. (2006a). Low-rank scale-invariant tensor product smooths for generalized additive mixed models. Biometrics, 62(4), 1025-1036.

Wood, S. (2006b). Generalized additive models: An introduction with R. Boca Raton, FL: Chapman \& Hall. 
Xu, G. \& Feiner, S. (2007). China's beauty economy: Buying looks, shifting value, and changing place. Feminist Economics, 13(3-4), 307-323.

Yan, Y. (2010). The Chinese path to individualization. British Journal of Sociology, 61(3), 489-512. 
Table 1: Descriptive Statistics

\begin{tabular}{|c|c|c|c|c|c|c|}
\hline & \multicolumn{2}{|c|}{ Rural } & \multicolumn{2}{|c|}{ Migrants } & \multicolumn{2}{|c|}{ Urban } \\
\hline & Male & Female & Male & Female & Male & Female \\
\hline SWB & 39.024 & 37.784 & 38.829 & 38.017 & 38.542 & 37.975 \\
\hline Height (cm) & 167.799 & 159.946 & 169.691 & 159.728 & 170.871 & 159.755 \\
\hline Weight (kg) & 64.035 & 56.597 & 65.313 & 55.155 & 68.720 & 57.366 \\
\hline BMI & 22.720 & 22.122 & 22.671 & 21.607 & 23.513 & 22.464 \\
\hline Underweight & 0.025 & 0.070 & 0.034 & 0.103 & 0.016 & 0.056 \\
\hline Healthy weight & 0.827 & 0.811 & 0.791 & 0.792 & 0.723 & 0.774 \\
\hline Overweight & 0.140 & 0.115 & 0.166 & 0.097 & 0.250 & 0.158 \\
\hline Obese & 0.008 & 0.004 & 0.009 & 0.007 & 0.011 & 0.012 \\
\hline Per capita income & 5894.00 & 5539.41 & 1412.26 & 1275.04 & 21181.07 & 21070.65 \\
\hline Log per capita income & 8.360 & 8.356 & 7.094 & 6.979 & 9.710 & 9.722 \\
\hline Age & 47.971 & 45.700 & 36.281 & 35.389 & 45.637 & 44.255 \\
\hline Household head & 0.982 & 0.060 & 0.905 & 0.500 & 0.776 & 0.425 \\
\hline Hukou urban & 0.060 & 0.059 & 0.012 & 0.011 & 0.954 & 0.946 \\
\hline Years of Education & 7.704 & 6.591 & 8.919 & 8.239 & 11.629 & 10.860 \\
\hline Married & 0.984 & 0.985 & 0.838 & 0.892 & 0.978 & 0.945 \\
\hline Zero children & 0.009 & 0.002 & 0.191 & 0.122 & 0.046 & 0.033 \\
\hline One child & 0.293 & 0.311 & 0.480 & 0.556 & 0.848 & 0.854 \\
\hline Two children & 0.465 & 0.463 & 0.279 & 0.280 & 0.092 & 0.097 \\
\hline Three or more children & 0.234 & 0.223 & 0.050 & 0.041 & 0.014 & 0.016 \\
\hline Very good health & 0.254 & 0.211 & 0.418 & 0.353 & 0.173 & 0.148 \\
\hline Good health & 0.512 & 0.500 & 0.434 & 0.481 & 0.493 & 0.492 \\
\hline Average health & 0.199 & 0.236 & 0.135 & 0.145 & 0.296 & 0.315 \\
\hline Poor health & 0.030 & 0.045 & 0.011 & 0.020 & 0.031 & 0.042 \\
\hline Very poor health & 0.005 & 0.007 & 0.002 & 0.001 & 0.007 & 0.003 \\
\hline Employed & 0.385 & 0.215 & 0.974 & 0.824 & 0.827 & 0.579 \\
\hline Disabled & 0.047 & 0.050 & 0.023 & 0.023 & 0.036 & 0.025 \\
\hline $\mathrm{N}$ & 4,942 & 3,706 & 2,482 & 1,448 & 2,043 & 3,117 \\
\hline
\end{tabular}

Notes: Sample are all household heads and spouses of the married household heads in sampled households between the ages of 25 and 60. Income is household per capita income. 
Table 2: OLS Results for SWB and Height

\begin{tabular}{|c|c|c|c|c|c|c|}
\hline & \multicolumn{2}{|c|}{ Rural } & \multicolumn{2}{|c|}{ Migrants } & \multicolumn{2}{|c|}{ Urban } \\
\hline & Male & Female & Male & Female & Male & Female \\
\hline \multirow[t]{2}{*}{ Height (cm) } & 0.015 & 0.021 & $0.043 * * *$ & 0.034 & 0.018 & 0.004 \\
\hline & $(0.010)$ & $(0.013)$ & $(0.015)$ & $(0.021)$ & $(0.017)$ & $(0.015)$ \\
\hline \multirow[t]{2}{*}{ Log per capita income } & 0.061 & 0.030 & $0.477 * * *$ & $0.484 * * *$ & $0.794 * * *$ & $0.854 * * *$ \\
\hline & $(0.064)$ & $(0.072)$ & $(0.139)$ & $(0.172)$ & $(0.133)$ & $(0.120)$ \\
\hline \multirow[t]{2}{*}{ Age } & -0.106 & $-0.274 * * *$ & 0.066 & 0.100 & -0.028 & $-0.143^{*}$ \\
\hline & $(0.082)$ & $(0.089)$ & $(0.077)$ & $(0.118)$ & $(0.096)$ & $(0.080)$ \\
\hline \multirow[t]{2}{*}{ Age squared } & 0.001 & $0.003 * * *$ & -0.001 & -0.001 & 0.000 & $0.002 *$ \\
\hline & $(0.001)$ & $(0.001)$ & $(0.001)$ & $(0.002)$ & $(0.001)$ & $(0.001)$ \\
\hline \multirow[t]{2}{*}{ Household head } & 0.394 & 0.174 & 0.286 & 0.155 & -0.107 & $0.441^{* * *}$ \\
\hline & $(0.400)$ & $(0.303)$ & $(0.251)$ & $(0.221)$ & $(0.197)$ & $(0.147)$ \\
\hline \multirow[t]{2}{*}{ Hukou urban } & $0.495 * *$ & -0.055 & 0.086 & 0.189 & 0.637 & 0.191 \\
\hline & $(0.229)$ & $(0.276)$ & $(0.662)$ & $(0.915)$ & $(0.399)$ & $(0.309)$ \\
\hline \multirow[t]{2}{*}{ Years of Education } & $0.091 * * *$ & $0.102 * * *$ & $0.151 * * *$ & 0.063 & $0.079 * * *$ & $0.049 * *$ \\
\hline & $(0.024)$ & $(0.028)$ & $(0.032)$ & $(0.042)$ & $(0.026)$ & $(0.025)$ \\
\hline \multirow[t]{2}{*}{ Married } & $1.139 * * *$ & $2.764 * * *$ & $0.956 * * *$ & $2.097 * * *$ & $1.503^{* * *}$ & $0.906 * * *$ \\
\hline & $(0.418)$ & $(0.591)$ & $(0.308)$ & $(0.480)$ & $(0.562)$ & $(0.309)$ \\
\hline \multirow[t]{2}{*}{ Zero children } & -0.932 & 2.004 & -0.144 & $1.723 * *$ & 0.718 & -0.106 \\
\hline & $(0.575)$ & $(1.280)$ & $(0.472)$ & $(0.695)$ & $(0.810)$ & $(0.685)$ \\
\hline \multirow[t]{2}{*}{ One child } & 0.094 & 0.344 & -0.100 & 0.137 & 0.948 & -0.243 \\
\hline & $(0.176)$ & $(0.210)$ & $(0.359)$ & $(0.512)$ & $(0.692)$ & $(0.550)$ \\
\hline \multirow[t]{2}{*}{ Two children } & 0.091 & $0.365 * *$ & -0.084 & 0.038 & $1.447 * *$ & -0.343 \\
\hline & $(0.142)$ & $(0.173)$ & $(0.354)$ & $(0.509)$ & $(0.726)$ & $(0.572)$ \\
\hline Three or more children & \multicolumn{6}{|c|}{ Reference group } \\
\hline Very good health & \multicolumn{2}{|c|}{ Reference group } & & & & \\
\hline \multirow[t]{2}{*}{ Good health } & $-1.710 * * *$ & $-2.073 * * *$ & $-1.419 * * *$ & $-1.536^{* * *}$ & $-1.731 * * *$ & $-1.938 * * *$ \\
\hline & $(0.130)$ & $(0.166)$ & (0.158) & $(0.216)$ & $(0.225)$ & $(0.200)$ \\
\hline \multirow[t]{2}{*}{ Average health } & $-2.753 * * *$ & $-3.334 * * *$ & $-2.549 * * *$ & $-2.712 * * *$ & $-3.232 * * *$ & $-3.599 * * *$ \\
\hline & $(0.164)$ & $(0.195)$ & $(0.226)$ & $(0.301)$ & $(0.253)$ & $(0.219)$ \\
\hline \multirow[t]{2}{*}{ Poor health } & $-5.282 * * *$ & $-6.269 * * *$ & $-4.708 * * *$ & $-3.352 * * *$ & $-6.698 * * *$ & $-5.990 * * *$ \\
\hline & $(0.332)$ & $(0.342)$ & $(0.677)$ & $(0.694)$ & $(0.513)$ & $(0.387)$ \\
\hline \multirow[t]{2}{*}{ Very poor health } & $-10.703^{* * *}$ & $-10.618 * * *$ & $-6.765 * * *$ & $-9.065 * * *$ & $-9.423 * * *$ & $-6.501 * * *$ \\
\hline & $(0.757)$ & $(0.761)$ & (1.581) & (2.573) & (1.015) & $(1.268)$ \\
\hline \multirow[t]{2}{*}{ Employed } & 0.038 & $0.338 * *$ & -0.512 & $-0.602^{* *}$ & $0.705 * * *$ & 0.066 \\
\hline & $(0.120)$ & $(0.172)$ & $(0.454)$ & $(0.283)$ & $(0.242)$ & $(0.162)$ \\
\hline \multirow[t]{2}{*}{ Disabled } & $-0.754 * * *$ & $-0.820 * * *$ & 0.027 & $-1.302^{* *}$ & -0.667 & -0.476 \\
\hline & $(0.260)$ & $(0.302)$ & $(0.470)$ & $(0.634)$ & $(0.447)$ & $(0.448)$ \\
\hline \multirow[t]{2}{*}{ Constant } & $38.985 * * *$ & $39.904 * * *$ & $26.277 * * *$ & $26.701 * * *$ & $25.974 * * *$ & $33.021 * * *$ \\
\hline & (2.697) & (2.951) & (3.236) & $(4.146)$ & $(3.897)$ & $(3.146)$ \\
\hline $\mathrm{N}$ & 4,942 & 3,706 & 2,482 & 1,488 & 2,043 & 3,117 \\
\hline R-Squared & 0.155 & 0.198 & 0.151 & 0.152 & 0.221 & 0.177 \\
\hline
\end{tabular}

Notes: $\quad$ 1. $* * * \mathrm{p}<0.01,{ }^{* *} \mathrm{p}<0.05, * \mathrm{p}<0.1$

2. Standard errors in parentheses.

3. Also controls for provincial dummies. 
Table 3: OLS Results for SWB and BMI (Continuous Variable)

\begin{tabular}{|c|c|c|c|c|c|c|}
\hline & \multicolumn{2}{|c|}{ Rural } & \multicolumn{2}{|c|}{ Migrants } & \multicolumn{2}{|c|}{ Urban } \\
\hline & Male & Female & Male & Female & Male & Female \\
\hline \multirow[t]{2}{*}{ BMI } & $0.052 * *$ & 0.035 & 0.005 & 0.010 & $0.093 * * *$ & $0.044 *$ \\
\hline & $(0.023)$ & $(0.025)$ & $(0.028)$ & $(0.037)$ & $(0.031)$ & $(0.025)$ \\
\hline \multirow[t]{2}{*}{ Log per capita income } & 0.062 & 0.021 & $0.475^{* * *}$ & $0.505^{* * *}$ & $0.791 * * *$ & $0.859 * * *$ \\
\hline & $(0.064)$ & $(0.072)$ & $(0.139)$ & $(0.172)$ & $(0.133)$ & $(0.120)$ \\
\hline \multirow[t]{2}{*}{ Age } & -0.113 & $-0.278 * * *$ & 0.049 & 0.108 & -0.038 & $-0.147^{*}$ \\
\hline & $(0.082)$ & $(0.090)$ & $(0.077)$ & $(0.118)$ & $(0.096)$ & $(0.080)$ \\
\hline \multirow[t]{2}{*}{ Age squared } & 0.001 & $0.003^{* * *}$ & -0.000 & -0.002 & 0.000 & $0.002 *$ \\
\hline & $(0.001)$ & $(0.001)$ & $(0.001)$ & $(0.002)$ & $(0.001)$ & $(0.001)$ \\
\hline \multirow{2}{*}{ Household head } & 0.420 & 0.176 & 0.298 & 0.128 & -0.127 & $0.442 * * *$ \\
\hline & $(0.400)$ & $(0.303)$ & $(0.251)$ & $(0.220)$ & $(0.197)$ & $(0.147)$ \\
\hline \multirow[t]{2}{*}{ Hukou urban } & $0.480 * *$ & -0.060 & 0.096 & 0.148 & 0.626 & 0.195 \\
\hline & $(0.229)$ & $(0.276)$ & $(0.663)$ & $(0.916)$ & $(0.398)$ & $(0.309)$ \\
\hline \multirow[t]{2}{*}{ Years of Education } & $0.089 * * *$ & $0.104^{* * *}$ & $0.158 * * *$ & 0.066 & $0.079 * * *$ & $0.052 * *$ \\
\hline & $(0.024)$ & $(0.028)$ & $(0.031)$ & $(0.042)$ & $(0.026)$ & $(0.025)$ \\
\hline \multirow[t]{2}{*}{ Married } & $1.131 * * *$ & $2.784 * * *$ & $0.959 * * *$ & $2.084 * * *$ & $1.510 * * *$ & $0.883 * * *$ \\
\hline & $(0.418)$ & $(0.591)$ & $(0.309)$ & $(0.480)$ & $(0.561)$ & $(0.309)$ \\
\hline \multirow{2}{*}{ Zero children } & -0.932 & 2.041 & -0.193 & $1.735 * *$ & 0.866 & -0.066 \\
\hline & $(0.575)$ & (1.279) & $(0.473)$ & $(0.697)$ & $(0.810)$ & $(0.685)$ \\
\hline \multirow[t]{2}{*}{ One child } & 0.089 & 0.344 & -0.126 & 0.116 & 1.048 & -0.192 \\
\hline & $(0.176)$ & $(0.210)$ & $(0.360)$ & $(0.513)$ & $(0.691)$ & $(0.551)$ \\
\hline \multirow[t]{2}{*}{ Two children } & 0.088 & $0.365 * *$ & -0.121 & 0.002 & $1.532 * *$ & -0.306 \\
\hline & $(0.142)$ & $(0.173)$ & $(0.354)$ & $(0.509)$ & $(0.725)$ & $(0.572)$ \\
\hline Three or more children & \multicolumn{6}{|c|}{ Reference group } \\
\hline Very good health & \multicolumn{6}{|c|}{ Reference group } \\
\hline \multirow[t]{2}{*}{ Good health } & $-1.701^{* * *}$ & $-2.081 * * *$ & $-1.420 * * *$ & $-1.546^{* * *}$ & $-1.722 * * *$ & $-1.941 * * *$ \\
\hline & $(0.130)$ & $(0.166)$ & $(0.159)$ & $(0.216)$ & $(0.225)$ & (0.199) \\
\hline \multirow[t]{2}{*}{ Average health } & $-2.729 * * *$ & $-3.348 * * *$ & $-2.582 * * *$ & $-2.718 * * *$ & $-3.252 * * *$ & $-3.613 * * *$ \\
\hline & $(0.164)$ & $(0.195)$ & $(0.227)$ & $(0.301)$ & $(0.252)$ & $(0.219)$ \\
\hline \multirow[t]{2}{*}{ Poor health } & $-5.258 * * *$ & $-6.300 * * *$ & $-4.697 * * *$ & $-3.329 * * *$ & $-6.756 * * *$ & $-5.994 * * *$ \\
\hline & $(0.332)$ & $(0.342)$ & $(0.678)$ & $(0.695)$ & $(0.512)$ & $(0.387)$ \\
\hline \multirow[t]{2}{*}{ Very poor health } & $-10.691^{* * *}$ & $-10.567^{* * *}$ & $-6.902 * * *$ & $-9.171^{* * *}$ & $-9.202 * * *$ & $-6.599 * * *$ \\
\hline & $(0.757)$ & $(0.762)$ & (1.583) & $(2.581)$ & $(1.015)$ & (1.269) \\
\hline \multirow[t]{2}{*}{ Employed } & 0.023 & $0.334 *$ & -0.450 & $-0.627 * *$ & $0.707 * * *$ & 0.070 \\
\hline & $(0.120)$ & $(0.172)$ & $(0.454)$ & $(0.282)$ & $(0.241)$ & $(0.162)$ \\
\hline \multirow[t]{2}{*}{ Disabled } & $-0.776 * * *$ & $-0.832 * * *$ & 0.004 & $-1.286 * *$ & -0.665 & -0.474 \\
\hline & $(0.259)$ & $(0.302)$ & $(0.471)$ & $(0.634)$ & $(0.446)$ & $(0.447)$ \\
\hline \multirow[t]{2}{*}{ Constant } & $40.550 * * *$ & $42.601 * * *$ & $33.772 * * *$ & $31.787 * * *$ & $27.118^{* * *}$ & $32.661 * * *$ \\
\hline & (2.089) & (2.217) & (1.978) & $(2.672)$ & $(2.735)$ & $(2.234)$ \\
\hline $\mathrm{N}$ & 4,942 & 3,706 & 2,482 & 1,488 & 2,043 & 3,117 \\
\hline R-Squared & 0.155 & 0.198 & 0.148 & 0.151 & 0.224 & 0.177 \\
\hline
\end{tabular}

Notes: $\quad$ 1. *** $\mathrm{p}<0.01, * * \mathrm{p}<0.05, * \mathrm{p}<0.1$

2. Standard errors in parentheses.

3. Also controls for provincial dummies. 
Table 4: OLS Results for SWB and BMI (Four Categories)



Notes: $\quad 1 .{ }^{* * *} \mathrm{p}<0.01,{ }^{* *} \mathrm{p}<0.05, * \mathrm{p}<0.1$

2. Standard errors in parentheses.

3. Also controls for provincial dummies. 
Figure 1: Migrants
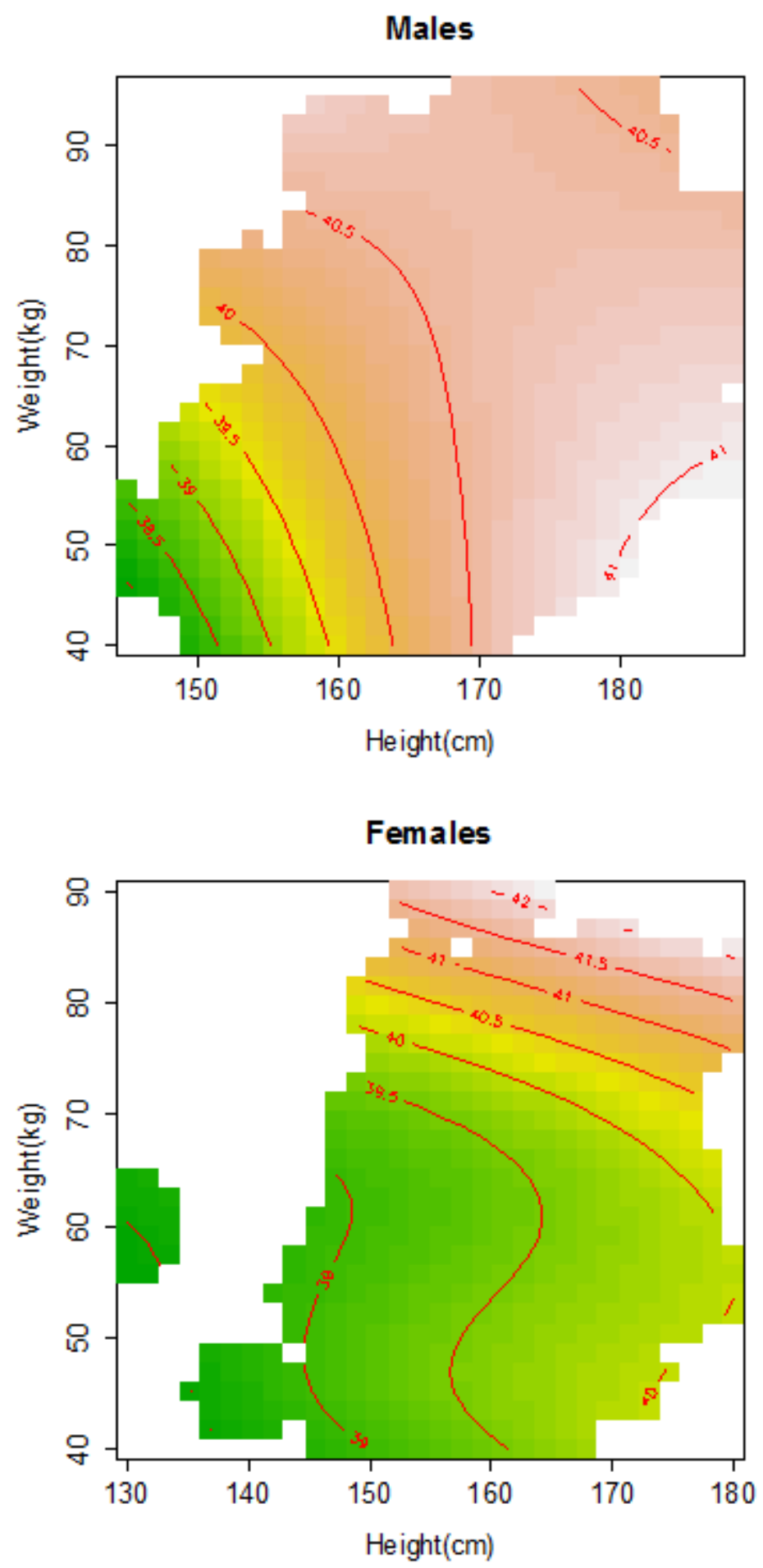

Notes: The model estimated includes the covariates listed in Table 1 and provincial dummies. 
Figure 2: Rural
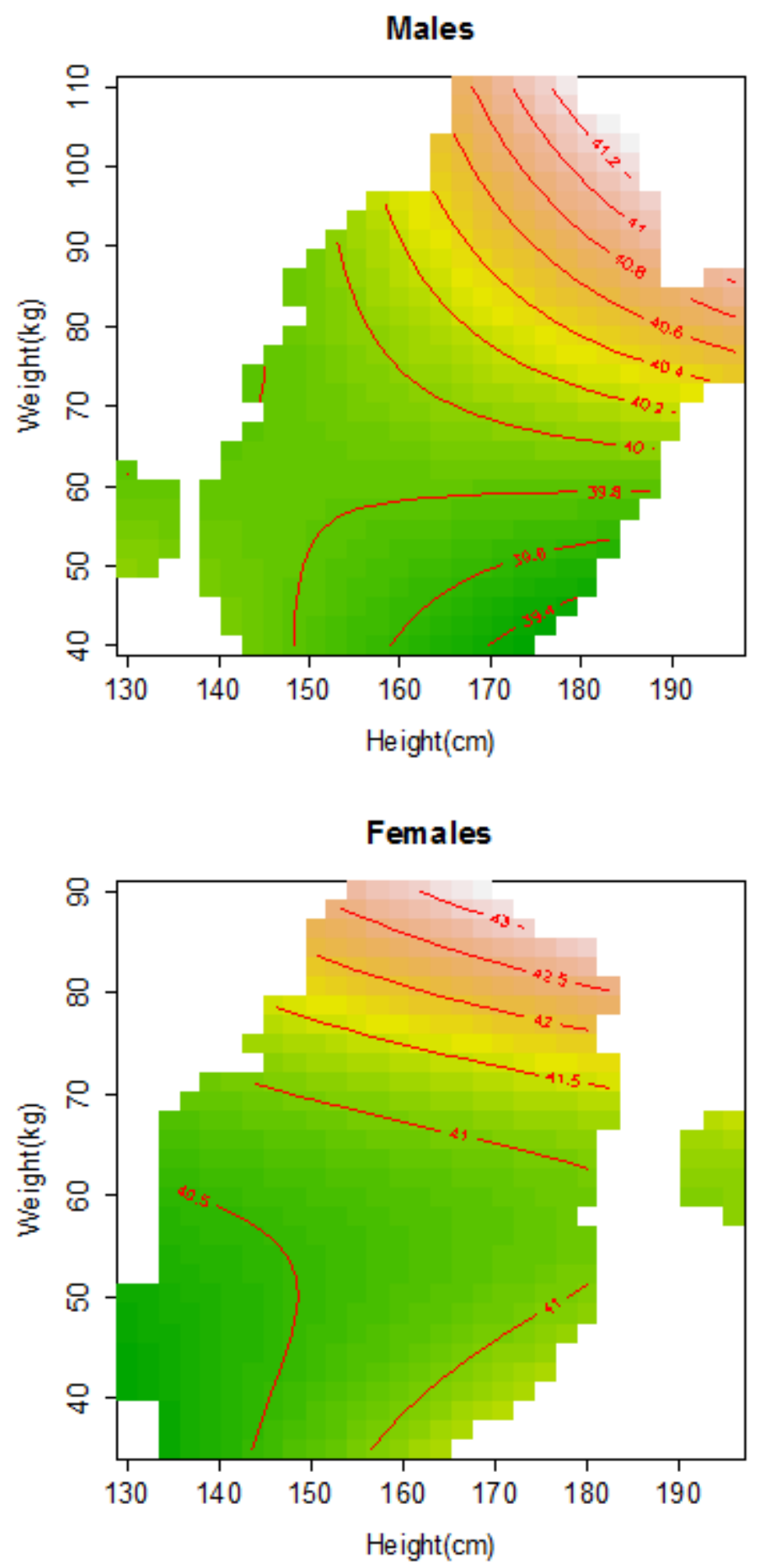

Notes: The model estimated includes the covariates listed in Table 1 and provincial dummies. 
Figure 3: Urban
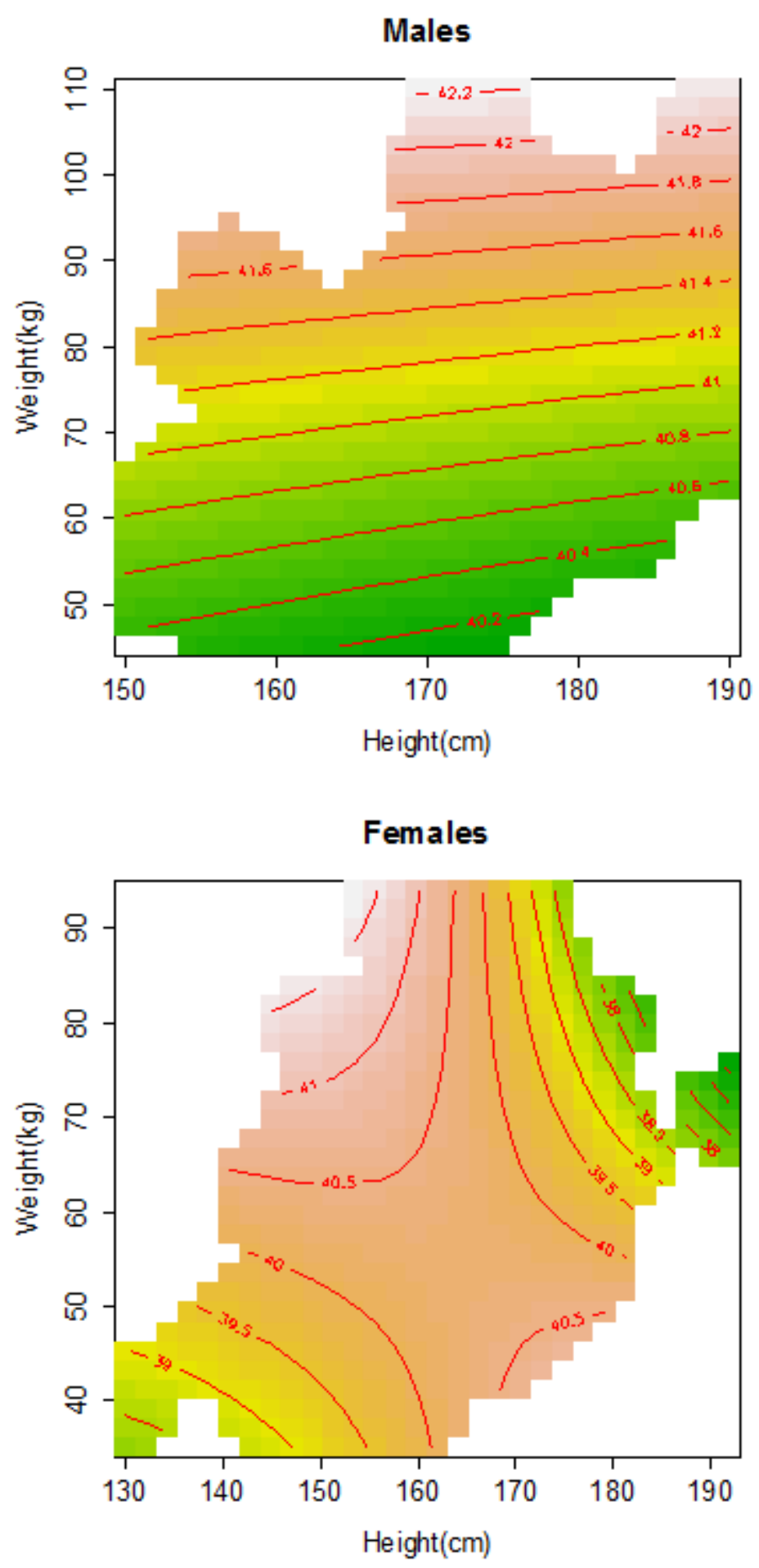

Notes: The model estimated includes the covariates listed in Table 1 and provincial dummies. 


\section{Appendix}

Table A.1: Results for SWB, Height and BMI

\begin{tabular}{lcccccc}
\hline & \multicolumn{2}{c}{ Rural } & \multicolumn{2}{c}{ Migrants } & \multicolumn{2}{c}{ Urban } \\
\cline { 2 - 7 } & \multicolumn{1}{c}{ Male } & Female & Male & Female & Male & Female \\
\hline Height & $0.046^{* * *}$ & $0.063^{* * *}$ & $0.060^{* * *}$ & $0.046^{* *}$ & $0.065^{* * *}$ & $0.045^{* * *}$ \\
& $(0.011)$ & $(0.013)$ & $(0.015)$ & $(0.021)$ & $(0.018)$ & $(0.016)$ \\
& & & & & & \\
\hline BMI (continuous) & $0.128^{* * *}$ & 0.042 & $0.048^{*}$ & -0.045 & $0.100^{* * *}$ & -0.039 \\
& $(0.023)$ & $(0.027)$ & $(0.028)$ & $(0.036)$ & $(0.034)$ & $(0.026)$ \\
\hline Healthy weight & Reference group & & & & & \\
Underweight & -0.353 & 0.210 & -0.230 & 0.292 & -0.259 & 0.116 \\
Overweight & $(0.354)$ & $(0.269)$ & $(0.409)$ & $(0.324)$ & $(0.686)$ & $(0.314)$ \\
Obese & $0.488^{* * *}$ & -0.019 & 0.197 & -0.458 & 0.157 & -0.083 \\
& $(0.160)$ & $(0.211)$ & $(0.200)$ & $(0.319)$ & $(0.207)$ & $(0.202)$ \\
& 0.522 & 1.559 & -1.089 & 1.121 & 0.637 & -0.688 \\
& $(0.628)$ & $(0.976)$ & $(0.793)$ & $(1.159)$ & $(0.854)$ & $(0.688)$ \\
\hline
\end{tabular}

Notes: $\quad$ 1. ${ }^{* * *} \mathrm{p}<0.01,{ }^{* *} \mathrm{p}<0.05$, $* \mathrm{p}<0.1$

2. Standard errors in parentheses.

3. Only controls for provincial dummies.

4. Coefficients in each panel and column are results from different regression models. 
Figure A.1: BMI and Household Income for the Urban Sample
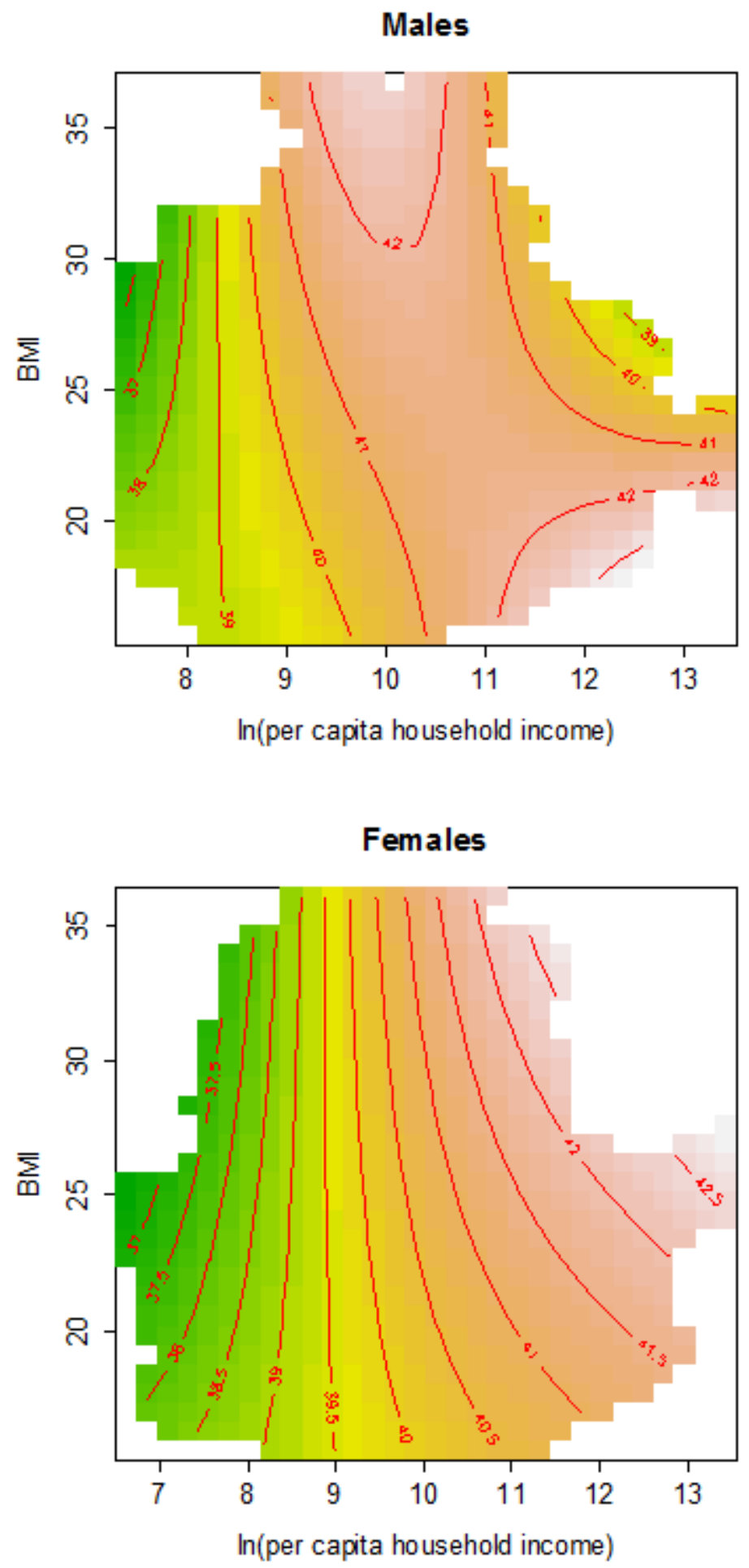

Notes: The model estimated includes the covariates listed in Table 1 and provincial dummies. 